\title{
Ex-ante Assessment of Urban Development Projects
}

\author{
By Attila Buzási ${ }^{1}$, Mária Szalmáné Csete ${ }^{1}$
}

\begin{abstract}
Budapest, the capital of Hungary facing several climatic challenges in the next decades, therefore there is a need of sustainable development projects with strong emphasis on the projected impacts of climate change. The main aim of the paper is to evaluate an ex-ante assessment methodology to analyse existence or absence of sustainability principles in renewal projects. The selected works have a focus on the same challenge, namely building an intermodal passenger transport hub and renewing the surrounding area in the district IV. of Budapest. The renewal plans have been developed by students from different Hungarian universities during a three-day-workshop. However the main focus of the workshop was on tackling the transport-based challenges, most of the elaborated plans have strong emphasis on green and blue areas, communities, building and related sustainability issues. The jury of the competition included mainly transportation engineers, real estate developers and civil engineers, therefore there is a need of involving broader sustainability and climate-related aspects into the assessment process. The output of the paper shall reveal the differences between developer-oriented ranking and the climate-related one regarding the same urban renewal challenge.
\end{abstract}

Keywords: urban sustainability; climate change; urban planning; ex-ante

\section{Introduction}

Current environmental and social challenges, such as climate change, environmental pollution and resource related issues indicate a huge demand on enhancing sustainability feature of urban development actions (Ji et al., 2017). Consequently, one of the most effective solutions for tackling complex sustainability challenges is to introduce and consequently apply sustainable urban development approaches. As an urban development project is inherently complex itself, there is a huge need for integrating interdisciplinary measures in both planning and construction phases of development projects (Sándor and Csiszár, 2015; Csete and Buzási, 2016; La Rosa et al., 2017).

It is worth mentioning that according to Laprise et al. (2015) urban development projects cannot be seen as fundamentally sustainable processes, however renewing a disuse or under-utilised area is crucial in urban policies, therefore it requires strong emphasis on social, environmental and economic aspects. Pediaditi et al. (2010) argued that unsustainable planning, construction and maintenance of green spaces of brownfield areas can be spectacular deficits of a given development project due to inadequate design practices. As current urban studies regarding renewal projects and brownfield development are focusing mainly on sustainability issues, there is less studies with aim of assessing climate-related aspects of urban development processes, such as mitigating greenhouse gas (GHG) emissions and adaptation to changing climatic (Balaban and De Oliveira, 2014). However, Heidrich et al. (2013) emphasised that integration of 
mitigation and adaptation issues into current redevelopment and renewal projects strongly and consequently contribute to urban sustainability.

Based on previously mentioned assumptions, the main aim of the present paper is to elaborate an ex-ante assessment method to evaluate sustainability and more specifically climate-orientation of selected urban plans with a focus on same urban development challenge in terms of a further developing project regarding the studied area. The evaluated plans are proposals to a three-day-workshop and competition organised by Special College of Transportation Engineering of the Budapest University of Technology and Economics. Students from different universities have been invited to attend the competition, thus six teams started to plan an intermodal passenger transport hub and to renewal existing buildings and surrounding area in the border of District IV. and XV. of Budapest, capital of Hungary. However, the main focus of the competition was firstly to tackle transportation challenges, architectural and sustainability aspects have been involved into the planning and later the assessment process. The developed evaluation method is basically climate-oriented, however it includes broader sustainability issues regarding direct and indirect social aspects. Moreover, it shall be emphasised that members of the jury that evaluated planning proposals were mainly transportation engineers, real estate developers and civil engineers, therefore the output of the paper shall reveal the differences between developer-oriented ranking and the climate-related one regarding the same urban renewal challenge.

\section{Literature Review}

The complexity of urban climate may take into consideration regarding effective urban adaptation due to urban morphological features, specific meteorological factors and spatial interactions of stakeholders (Steeneveld et al., 2016) which can be seen as critical issues regarding brownfield development. Literature of urban brownfield regeneration includes numerous studies emphasising the role of sustainability issues in planning and construction phases. According to Pediaditi et al. (2010) brownfield regeneration projects are labelled as definitely sustainable ones, moreover there is a widely accepted assumption regarding extensive amount of green spaces are involved into these projects. In parallel with this assumption, Dale and Newman (2009) stated that several brownfield and urban renewal projects distinguish sustainability as a dedicated and main aim. The role of sustainable urban development has been emphasised by also Gualini and Majoor (2007), since large-scale urban development projects have become the target of critics regarding sustainability aspects involved into development aspects. As it was declared above, main aim of present study is to elaborate an assessment framework to evaluate climate-based sustainability of given urban renewal plans. From this perspective, existing methodology approaches regarding development projects have been collected and studied. Brown et al. (2016) emphasised that there is no commonly and widely accepted methodology for selecting monitoring and assessment framework of urban climate resilience initiatives, however continuously increasing amount of studies have released with regards to methodology selection. Closely linked to previously cited study, Mneimneh et al. (2016) declared that there is no internationally accepted assessment approach with regards to sustainability aspects on micro and neighbourhood 
scale, however numerous evaluation tool existing concerning large-scale projects. In parallel with micro or neighbourhood scale, the role of social sustainability must be emphasised, because in a case of comprehensive renewal project, further operation of a given urban space largely determines the quality of life of local residents. In parallel with this, Glasson and Wood (2009) underlined the social aspects of urban regeneration projects, whether what social sustainability issues can be involved into built environment industry. Based on this assumption, a sustainability assessment approach has been developed to measure social issues regarding urban regeneration mention previously.

Among the above mentioned aspects, another critical factor is existing in the literature which reflects to adaptive planning and closely related to the need of assessment of projects in an ex-ante way. According to previously cited Glasson and Wood (2009) design flexibility is a highly important part of a given urban development project, since communities can be involved into both planning and constructing phase. However, in case of project proposals studied in this paper, community involvement could not be taken into consideration due to short period of planning phase, but it is worth mentioning that human face of urban development projects is definitely critical with regards to sustainability and climate-oriented criteria. Finally, according to Ambarwaiti et al. (2017) also stated that main aim of urban development projects is to increase and optimise the citizens' welfare, consequently decisions may include a strong communityorientation during the planning phase.

Regarding consideration of climate-related aspects in terms of sustainable urban development and renewal projects, Helbron et al. (2011) stated that magnitude of projected impacts of climate change requires strong integration of adaptation measures into planning stage, applying them as an early warning function of strategies, plans and development documents. Gaitani et al. (2014) also declared after a comprehensive and detailed literature review that climate-conscious planning or urban spaces contributes to avoid unsustainable urban development projects. Heidrich et al. (2013) assessed climate preparedness of $30 \mathrm{UK}$ urban areas and argued the need for involving mitigation and adaptation measures into development processes.

Summarising, after the review of related literature it can be stated that integration of climate issues into a sustainability-based assessment framework is proved and necessary. However, there is no rigid guideline for evaluating sustainability of urban development projects, involvement of climate-related issues is often lacking in the literature, therefore integrating adaptation and mitigation aspects into an ex-ante project evaluation approach is needed and shall expand the relevant literature.

\section{Methodology}

Beyond the above cited studies regarding evaluation of urban development projects in terms of sustainability and climate-orientation, additional review of current literature with strong focus on methodological challenges and solutions was needed to elaborate the assessment system of present paper. As it was stated above by some studies, there is no internationally accepted methodology to assess sustainability or climate-related issues of urban development projects. In the following, a brief highlight of relevant studies reveals complexity of evaluation approaches on different spatial scales 
and divergent sectors, however all of them focusing on the assessment of a given development process. Kao et al. (2017) examined urban strategic documents concerning reducing negative consequences of climate change and mitigating greenhouse gas emissions. Critical elements of strategies which may contribute to develop adaptationoriented plans have been defined in terms of land use, infrastructure or disaster prevention issues. Dedicated recommendations have been identified regarding to water bodies, ecological land use, flood protection, building rainwater sewer systems, designing disaster-resistant buildings and compact land use development. Wende et al (2012) applied a three-scale evaluation framework in the evaluation of climate-consciousness of regional plans. In their study, plus sign represents a given topic in a given plan that included climate change issues, zero means a slight consideration of adaptation or mitigation and minus concerned to topics in a given plan without any consideration of aspects regarding climate change. Same three-scale framework was applied previously by Csete and Buzási (2016) in studying climate-orientation of main street removal projects in an ex-post evaluation due to the easy-to-use feature of the evaluation approach.

Peliaditi et al. (2010) summarised tools which can be applied to assess sustainability of brownfield development projects and distinguished related aspects. Cavalcanti et al. (2017) developed an assessment approach with a set of 17 indicators, thus sustainability of urban mobility projects in economic, social and environmental categories can be evaluated. Helbron et al. (2011) elaborated a set of indicators to evaluate site-specific impacts of regional land use planning. The site-specific orientation of the study attracts emphasised attention in developing own assessment approach of present study.

Methodological approach applied by present paper is based on above cited studies and completed with selected works, such as van Leeuwen et al. (2006), Balaban and de Oliveira (2014), Mehta (2014), Smith (2014), and Laprise et al. (2015). The elaborated framework consists of 12 indicators regarding adaptation, 7 indicators considering mitigation aspects and finally 12 indicators with regards to broader sustainability issues (see Table 1.). As it was mentioned above, present paper aims to assess climate-related sustainability of urban development projects, consequently majority of indicators can be defined as climate-oriented ones. Since adaptation and mitigation issues should be interpreted as a specific dimension of sustainability, all of indicators can be seen as sustainability ones, still a dedicated category with 12 indicators has been selected to evaluate sustainability of projects from a more general interpretation of locally defined sustainable development. The assessment approach applies a four-step evaluation method from 0 to 3, whether a given aspect in a given proposal is "not considered", "slightly considered", "considered" or "consciously considered". Main difference between "considered" and "consciously considered" is whether a given solution is clearly distinguished in the technical description or during the presentation of the project or it only can be seen during the visualisation process. 
Table 1. Selected indicators to evaluate climate-orientation and sustainability of the proposals

\begin{tabular}{|c|c|c|}
\hline \multicolumn{3}{|c|}{ Adaptation } \\
\hline $\begin{array}{l}\text { Climatic comfort of the space- } \\
\text { shade and shelters }\end{array}$ & \begin{tabular}{|lr} 
Air & exchange \\
corridors/cold air flows
\end{tabular} & Water savings, reduced consumption \\
\hline Rainwater recycling for reuse & $\begin{array}{l}\text { Enhance ecological land- } \\
\text { use }\end{array}$ & $\begin{array}{l}\text { Increase the coverage of rainwater } \\
\text { sewer systems }\end{array}$ \\
\hline \begin{tabular}{|lrl}
$\begin{array}{l}\text { Tree-lined } \\
\text { streetscapes }\end{array}$ & and shaded \\
\end{tabular} & \begin{tabular}{|lll}
$\begin{array}{l}\text { Create } \\
\text { spaces }\end{array}$ & pocket green \\
\end{tabular} & $\begin{array}{l}\text { Site design for wetlands and water } \\
\text { bodies }\end{array}$ \\
\hline \begin{tabular}{|l} 
Climate-resistant designs and \\
materials
\end{tabular} & $\begin{array}{l}\text { Water-appropriate } \\
\text { plantings }\end{array}$ & $\begin{array}{l}\text { Local climate-oriented plant/tree } \\
\text { selections }\end{array}$ \\
\hline \multicolumn{3}{|c|}{ Mitigation } \\
\hline $\begin{array}{l}\text { Reduction of individual } \\
\text { motorisation rate }\end{array}$ & $\begin{array}{l}\text { Prioritization of public } \\
\text { transportation }\end{array}$ & 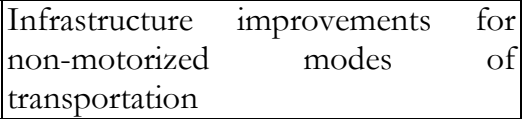 \\
\hline Reduced parking footprint & $\begin{array}{l}\text { Optimize building energy } \\
\text { performance }\end{array}$ & $\begin{array}{l}\text { Renewable energy for buildings in } \\
\text { operation }\end{array}$ \\
\hline \begin{tabular}{|lrrr} 
Solar & power & photovoltaic \\
energy & sources & except & of \\
buildings & & & \\
\end{tabular} & & \\
\hline \multicolumn{3}{|c|}{ Sustainability } \\
\hline Noise reduction & \begin{tabular}{|lll}
$\begin{array}{l}\text { Presence of sport } \\
\text { facilities }\end{array}$ &
\end{tabular} & $\begin{array}{l}\text { Presence of additional recreational } \\
\text { facilities }\end{array}$ \\
\hline \begin{tabular}{|lll}
$\begin{array}{l}\text { Presence of facilities for } \\
\text { children }\end{array}$ & \\
\end{tabular} & $\begin{array}{l}\text { Project compatibility } \\
\text { with the master plan }\end{array}$ & \begin{tabular}{|llll}
$\begin{array}{l}\text { Conserve natural and cultural } \\
\text { heritage }\end{array}$ & & \\
\end{tabular} \\
\hline Mixed-use land development & $\begin{array}{l}\text { Utilisation of existing } \\
\text { buildings }\end{array}$ & $\begin{array}{l}\text { Promote social affluence and } \\
\text { community prosperity }\end{array}$ \\
\hline \begin{tabular}{|lll}
$\begin{array}{l}\text { Physical connection } \\
\text { openness }\end{array}$ & and \\
\end{tabular} & Accessibility & Reduction of expropriations \\
\hline
\end{tabular}

Source: own compilation based on revised literature

\section{Planning Area}

The planning area was Rákospalota-Újpest railway station and the surrounding area, located on the northern part of Budapest, on the border of District IV. (Újpest) and District XV. (Rákospalota). The station has seven platforms, however some of them are underutilised and dangerous to passengers due to the short distance between them. The main building is completely run-down and seems to be as 50-60 years ago, as well as there is a second run-down building behind the main one which was a warehouse in the past. In the centre of the site there is a footbridge which links the two districts over the platforms, however its usage is quite moderate, because passengers usually come across the platforms (see Figure 1). On the eastern part of area a tram stop of two lines can be found which offers direct link to final station of metro line M3 at Újpest-Központ, about 2 kilometres from the railway station. Moreover there is an under-utilised bus stop on the south-eastern part of the area. An extensive, less-used industrial area is situated also on the eastern part. Among the train lines, typical land use can be defined as low-density residential area with extended noise pollution due to the vicinity of platforms.

In general, it can be stated that Rákospalota-Újpest railway station and the surrounding 
area is ready to a comprehensive renewal project. Based on the need of people living in the surrounding area and passengers, creating a new and comfortable transport hub with extensive green areas shall be created by paying dedicated attention to sustainability and climate-friendliness. Moreover, a well-planned and adequately utilised landscape can attract economic activities and real estate developers, therefore economic dimension of sustainability can also be enhanced. The need of residents to a liveable and comfortable urban space is undoubtedly clear, however the respect of both existing cultural heritages and of low-density residential area is required to create a really sustainable new urban place.
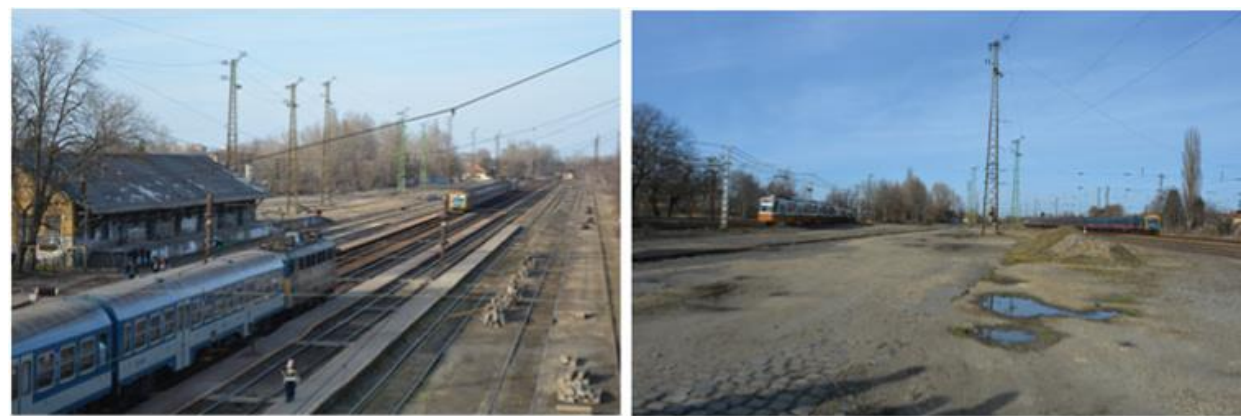

Figure 1. Landscape from the footbridge (on left) and disused area behind the warehouse (on right) Source: photos taken by organisers of the competition (http:/ / www.varostervezesinapok. hu)

Challenges shall to be tackled during the competition are summarised in the followings: complex reconstruction of the railway station in terms of transportation needs; renovation of existing buildings; enhancing connection between the two districts; improving intermodal passenger transport; analysing public transport cycling routes opportunities; meeting parking needs; improving green spaces and the utilisation of under-utilised industrial sites. Summarising, it can be stated that required actions are strongly transport-oriented, however some sustainability and green space-related issues with less attention are also emerging. Finally, the above mentioned tasks were completed with a highly important presumption: the extended metro line M3 will have an underground station at the planning area, so intermodal feature of the site will be heavily strengthened in the future, thus an increased passenger load shall to be taken into consideration in the proposals.

\section{Results}

Before introducing the result of present paper by applying previously mentioned evaluation scheme, brief summary of proposals shall be worth mentioning. The main design objectives of the competition addressed an inherently transport-oriented renewal of the site, however building renovation and green space development have also been involved. Team 1 reallocated the platforms about 200 metres in south; developed a P+R place 200 metres from main building; demolished existing but run-down residential building along the planned intermodal hub; created a green corridor between platforms 
and nearby neighbourhoods with noise reduction function and finally increased green areas with expanded bicycle routes and drought-tolerant plants. The most innovative action regarding green areas was to develop a green corridor over platforms to connect IV. and XV. Districts of Budapest in order to revitalise communities and to enhance ecological land-use in a former brownfield. Team 2 consisted of mainly landscape architect students, therefore particular emphasis was put on green area improvement rather than transport planning aspects: along the platforms an extensive green area was planned with emphasis on local climatic features and noise reduction function; a largescale green corridor with various type of recreation and sport facilities, and playgrounds was developed over the platforms; wastewater recycling was taken into consideration; retail development and complex renovation of existing building have also been involved into the project, finally a lighter amount of expropriation became inevitable. Main renewal actions from the proposal of Team 3 can be summarised as the followings: a regional and urban bus parking place in northern edge of the site, behind the former warehouse; enlarging bicycle path system; a two-storey parking house with green facade near to the main building; improvement of pedestrian safety by speed reduction and dedicated crossings; complex utilisation of existing buildings and trees; developing a green promenade with various recreational facilities, climate-resistant plants and water bodies. Proposal of Team 4 put emphasis on transport-oriented and social issues, thus main development elements are the followings: traffic calming and prioritising publictransport and non-motorised transport modes along the intermodal hub; indirect impacts on surrounding $\mathrm{P}+\mathrm{R}$ issues regarding suburban areas; linking the two districts; promotion of social affluence by creating liveable and connected public spaces with recreational and sport facilities and playgrounds; developing a small agora and innovative utilisation of run-down warehouse building. Similar to Team 4, main aspects of proposed plan by Team 5 was also focusing on people-oriented solutions completed with transport-centred perspective, so the most important actions are the followings: underground $\mathrm{P}+\mathrm{R}$ places; developing a local brand with a focus on people living in surrounding areas by creating extensive green areas with social functions (street gym, historic park, water bodies, playgrounds, outdoor chess tables) while tearing down existing main building and former warehouse. Finally, Team 6 ignored existing master plans of Budapest, therefore the most innovative actions have been distinguished: developing a completely new tram-train system and connecting suburban areas and downtown of Budapest; P+R opportunities at both ends of the site; creating extensive green areas with climate-resistant plants, water bodies to improve microclimatic comfort; noise reduction along the platforms.

After the evaluation process, final ranking of proposals has been made by the jury (each of 9 member evaluated the projects in a 100-point-scheme, so maximum value was altogether 900 points to a given proposal). Team 6 won the first prize with 814 points, Team 4 was on $2^{\text {nd }}$ place with 755 points, Team 3 proposed the $3^{\text {rd }}$ prize project with 739 points, Team 1 was on $4^{\text {th }}$ place with 688 points, $5^{\text {th }}$ place went to Team 5 with 684 points and finally, Team 2 was on $6^{\text {th }}$ place with 552 points. In the following paragraphs, a different evaluation approach of proposals is introduced, based on climate-related and more general sustainability aspects in order to be able to compare results from the two assessment methods. 
Indicators of adaptation dimension have strong emphasis on evaluating resilience of proposed urban development plans, because aspects range from shading issues through utilisation of green spaces to water-related topics (see Table 2). Each indicator is qualitative ones, therefore complete evaluation process can be conducted without huge amount of expensive and inaccessible data. Team 3 and Team 2 won the $1^{\text {st }}$ and $2^{\text {nd }}$ prize regarding adaptation issues with 30 and 29 of maximum 36 points. These proposals had a strong focus on water-utilisation, shading issues and locally suitable opportunities by selecting local climate-oriented plants and trees, moreover water bodies have also been planned by Team 3. Unlike the other teams, proposals of both Team 2 and Team 3 have taken climate-resistance into consideration in terms of design and materials. Team 6 has been ranked to $3^{\text {rd }}$ place with extensive green areas, enhanced ecological land-use completed by designing for wetlands and water bodies on large part of the site. Unfortunately notable amount of points regarding rainwater harvesting and recycling and climate-resistance of materials is lacking. Team 1 and Team 5 were put on $4^{\text {th }}$ and $5^{\text {th }}$ places, with less emphasis on adaptation aspects during planning process, however some good practices incorporated into their proposals can be identified: enhancing ecological land-use, water-appropriate plantings and local climate-oriented selection of trees and plants in case of proposal of Team 1, moreover planning new water bodies by Team 5 . Team 4 put the less attention to adaptation issues with a complete lack of rainwater utilisation, climate-resilient design and water-appropriateness of plantings.

In summary it can be stated that incorporation of adaptation issues into proposals varies from total consciousness to almost complete lack of resilient aspects. However numerous good practices and innovative solutions has been identified and developed by the teams, therefore a good basis for taking further aspects into consideration can be realisable to achieve resilient and sustainable complex brownfield development plans.

Table 2. Adaptation issues in evaluating proposals

\begin{tabular}{|l|c|c|c|c|c|c|}
\hline & Team 1 & Team 2 & Team 3 & Team 4 & Team 5 & Team 6 \\
\hline Climatic comfort of the space-shade and shelters & 1 & 3 & 2 & 1 & 2 & 1 \\
\hline Air exchange corridors & 1 & 2 & 1 & 1 & 1 & 2 \\
\hline Water savings, reduced consumption & 0 & 2 & 2 & 0 & 0 & 2 \\
\hline Rainwater recycling for reuse & 0 & 3 & 3 & 0 & 0 & 0 \\
\hline Enhance ecological land-use & 3 & 3 & 3 & 2 & 2 & 3 \\
\hline Increase the coverage of rainwater sewer systems & 0 & 3 & 3 & 0 & 0 & 0 \\
\hline Tree-lined and shaded streetscapes & 2 & 3 & 3 & 2 & 3 & 3 \\
\hline Create pocket green spaces & 2 & 2 & 2 & 1 & 2 & 2 \\
\hline Site design for wetlands and water bodies & 0 & 0 & 3 & 0 & 3 & 3 \\
\hline Climate-resistant designs and materials & 0 & 2 & 2 & 0 & 0 & 0 \\
\hline Water-appropriate plantings & 3 & 3 & 3 & 0 & 0 & 3 \\
\hline Local climate-oriented plant/ tree selections & 3 & 3 & 3 & 0 & 0 & 3 \\
\hline $\boldsymbol{\Sigma}$ & $\mathbf{1 5}$ & $\mathbf{2 9}$ & $\mathbf{3 0}$ & $\mathbf{7}$ & $\mathbf{1 3}$ & $\mathbf{2 2}$ \\
\hline
\end{tabular}

Source: own compilation

Evidence of mitigation aspects in a given proposal has been evaluated by using 7 indicators, thus a maximum of 21 points can be collected by teams (see Table 3). Because of transport-orientation of design objectives, a massive implementation of 
mitigation-oriented aspects should be presumable. However both Team 3 and Team 4 achieved 15 points and the $1^{\text {st }}$ place in a tie in this category. Proposal of Team 3 provided numerous great solutions and innovative actions regarding indirect GHG reduction and prioritising non-motorised and public transport modes, however renewable energy sources have not been used except of building. Team 4 has paid less attention to reduce parking footprint of the site and to optimise building energy performance, while solar panels have been assessed to install on the top of roof of platforms which is a remarkably innovative action. Team 1 and Team 6 got 0 points in case of energy issues, therefore considerable amount of points have not been accounted due to the lack of architectural solutions with regard to reduce GHG emissions through buildings. In summary it can be stated that proposals has less taken mitigation issues into consideration, consequently consciousness of that aspects shall be increased in the planning stage.

Table 3. Mitigation issues in evaluating proposals

\begin{tabular}{|l|c|c|c|c|c|c|}
\hline & $\begin{array}{c}\text { Team } \\
\mathbf{1}\end{array}$ & $\begin{array}{c}\text { Team } \\
\mathbf{2}\end{array}$ & $\begin{array}{c}\text { Team } \\
\mathbf{3}\end{array}$ & $\begin{array}{c}\text { Team } \\
\mathbf{4}\end{array}$ & $\begin{array}{c}\text { Team } \\
\mathbf{5}\end{array}$ & $\begin{array}{c}\text { Team } \\
\mathbf{6}\end{array}$ \\
\hline Reduction of individual motorisation rate & 2 & 2 & 2 & 3 & 1 & 1 \\
\hline Prioritization of public transportation & 1 & 2 & 2 & 3 & 2 & 1 \\
\hline $\begin{array}{l}\text { Infrastructure improvements for non-motorized } \\
\text { modes of transportation }\end{array}$ & 3 & 3 & 3 & 2 & 3 & 3 \\
\hline Reduced parking footprint & 0 & 2 & 3 & 0 & 3 & 2 \\
\hline Optimize building energy performance & 0 & 2 & 2 & 1 & 0 & 0 \\
\hline Renewable energy for buildings in operation & 0 & 0 & 3 & 3 & 0 & 0 \\
\hline $\begin{array}{l}\text { Solar power photovoltaic energy sources except of } \\
\text { buildings }\end{array}$ & 0 & 0 & 0 & 3 & 0 & 0 \\
\hline $\mathbf{\Sigma}$ & $\mathbf{6}$ & $\mathbf{1 1}$ & $\mathbf{1 5}$ & $\mathbf{1 5}$ & $\mathbf{9}$ & $\mathbf{7}$ \\
\hline
\end{tabular}

Source: own compilation

Development-oriented sustainability issues have been involved into the assessment scheme elaborated in present paper by using 12 indicators with maximum of 36 points can be reached by a given project. It can be seen in Table 4., that noise reduction and enhancing physical connections are the two best-performed categories, where each team reached 3-3 points. Team 3 collected 33 of 36 points, means $90 \%$ of total achievable points, without lack of any categories. It can be stated all sustainability categories have been well involved into proposal of Team 3, therefore sustainability of the whole projects is unimpeachable in this case. On the second place, Team 2 performed slightly weaker than Team 3, consequently two aspects, such as conservation of cultural heritage and reduction of expropriations shall be more emphasised. It is worth mentioning that these two teams were the leaders in case of adaptation as well. The weakest performance has been provided by Team 1 with a complete or almost complete lack of appropriate actions in the fields of recreational, sport and children facilities, conservation of cultural heritage, social inclusion and reduction of expropriations.

In summary, the final ranking of proposals with using climate-based sustainability is the following: Team 3 (78 pts), Team 2 (69 pts), Team 6 (52 pts), Team 4 (47 pts), Team 5 (46 pts) and Team 1 (38 pts). Detailed analysis between rankings can be found in the 
next section, however it can be stated that final results of the two methods are inherently different.

Table 4. Broader sustainability issues in evaluating proposals

\begin{tabular}{|l|c|c|c|c|c|c|}
\hline & Team 1 & Team 2 & Team 3 & Team 4 & Team $\mathbf{5}$ & Team $\mathbf{6}$ \\
\hline Noise reduction & 3 & 3 & 3 & 3 & 2 & 3 \\
\hline Presence of sport facilities & 1 & 3 & 3 & 3 & 3 & 1 \\
\hline Presence of additional recreational facilities & 1 & 3 & 3 & 3 & 3 & 2 \\
\hline Presence of facilities for children & 0 & 3 & 2 & 3 & 2 & 1 \\
\hline Project compatibility with the master plan & 2 & 2 & 3 & 2 & 2 & 0 \\
\hline Conserve natural and cultural heritage & 0 & 1 & 3 & 0 & 3 & 1 \\
\hline Mixed-use land development & 2 & 2 & 3 & 1 & 2 & 2 \\
\hline Utilisation of existing buildings & 2 & 2 & 3 & 3 & 0 & 2 \\
\hline Promote social affluence and community prosperity & 0 & 3 & 2 & 3 & 3 & 3 \\
\hline Physical connection and openness & 3 & 3 & 3 & 3 & 3 & 3 \\
\hline Accessibility & 3 & 3 & 3 & 0 & 0 & 3 \\
\hline Reduction of expropriations & 0 & 1 & 2 & 1 & 1 & 2 \\
\hline $\mathbf{\Sigma}$ & $\mathbf{1 7}$ & $\mathbf{2 9}$ & $\mathbf{3 3}$ & $\mathbf{2 5}$ & $\mathbf{2 4}$ & $\mathbf{2 3}$ \\
\hline
\end{tabular}

Source: own compilation

\section{Summary and Conclusion}

The first aim of this paper concerned to elaborate It can be stated that the elaborated set of indicators is an easy-to-use decision support tool, which can be applied without need of collecting expensively developed or hard-to-available data. All of indicators are qualitative ones, therefore filling them with values is easier than applying quantitative and more sophisticated indicators. Apart from simplicity of indicators, they can be easily applied to reveal strengthens and weaknesses of a given project regarding adaptation, mitigation and broader sustainability dimensions by using scores from 0 to 3 . The developed evaluation scheme provides opportunity to planners and decision-makers to assess universally agreed aspects of urban development processes in an ex-ante way, since applied indicators are inherently not local-specific, however they help to define locally suitable opportunities in parallel with ranking of urban brownfield development proposals in terms of sustainability.

As it was stated above, jury consisted of experts mainly from transport sector, therefore the most emphasised aspect during the evaluation process was development of transport-related areas. Since one of the main aims of present paper was to reveal potential differences between transport-, and climate-based sustainability-oriented approaches, comparison of final results can be definitely proved the assumption about differences. It can be argued that applying a climate-based sustainability evaluation framework has been paying more attention to aspects that seem to be underemphasised previously. For example Team 2 which was on $6^{\text {th }}$ place in the competition, performing really well in case of climate-oriented assessment method and it was finally ranked to $2^{\text {nd }}$ place with a massive increased total point. Another example is the case of Team 6 which was the first prize winner in the competition owing to highly innovative transport planning solutions, such as a new tram-train system and the reorganisation of existing 
tram lines. Nevertheless, from climatic and sustainability point of view, some aspects were lacking in the proposal, therefore Team 6 had $3^{\text {rd }}$ highest score when sustainabilityand climate-related issues have been taken into consideration. Consequently it can be stated that involving sustainability and climate-related into the initial evaluation method entails modified final ranking, and emphasised involvement of sustainability aspects into an ex-ante assessment of urban development projects.

\section{References}

Ambarwati, L., Verhaeghe, R., Arem, B., \& Pel, A. (2017). Assessment of transport performance index for urban transport development strategies - Incorporating residents' preferences. Environmental Impact Assessment Review, 63, 107-115.

Balaban, O., \& Puppim de Oliveira, J. (2013). Understanding the links between urban regeneration and climate-friendly urban development: lessons from two case studies in Japan. Local Environment, 19(8), 868-890.

Brown, C., Shaker, R., \& Das, R. (2016). A review of approaches for monitoring and evaluation of urban climate resilience initiatives. Environment, Development And Sustainability.

Cavalcanti, C., Limont, M., Dziedzic, M., \& Fernandes, V. (2017). Sustainability assessment methodology of urban mobility projects. Land Use Policy, 60, 334-342.

Csete, M., \& Buzasi, A. (2016). Climate-oriented assessment of main street design and development in Budapest. Journal Of Environmental Engineering And Landscape Management, 24(4), 258-268.

Dale, A., \& Newman, L. (2009). Sustainable development for some: green urban development and affordability. Local Environment, 14(7), 669-681.

Gaitani, N., Santamouris, M., Cartalis, C., Pappas, I., Xyrafi, F., \& Mastrapostoli, E. et al. (2014). Microclimatic analysis as a prerequisite for sustainable urbanisation: Application for an urban regeneration project for a medium size city in the greater urban agglomeration of Athens, Greece. Sustainable Cities And Society, 13, 230-236.

Glasson, J., \& Wood, G. (2009). Urban regeneration and impact assessment for social sustainability. Impact Assessment And Project Appraisal, 27(4), 283-290.

Gualini, E., \& Majoor, S. (2007). Innovative Practices in Large Urban Development Projects: Conflicting Frames in the Quest for "New Urbanity". Planning Theory \& Practice, 8(3), 297-318.

Heidrich, O., Dawson, R., Reckien, D., \& Walsh, C. (2013). Assessment of the climate preparedness of 30 urban areas in the UK. Climatic Change, 120(4), 771-784.

Helbron, H., Schmidt, M., Glasson, J., \& Downes, N. (2011). Indicators for strategic environmental assessment in regional land use planning to assess conflicts with adaptation to global climate change. Ecological Indicators, 11(1), 90-95.

Ji, Q., Li, C., \& Jones, P. (2017). New green theories of urban development in China. Sustainable Cities And Society, 30, 248-253.

La Rosa, D., Privitera, R., Barbarossa, L., \& La Greca, P. (2017). Assessing spatial benefits of urban regeneration programs in a highly vulnerable urban context: A case study in Catania, Italy. Landscape And Urban Planning, 157, 180-192.

Laprise, M., Lufkin, S., \& Rey, E. (2015). An indicator system for the assessment of sustainability integrated into the project dynamics of regeneration of disused urban areas. Building And Environment, 86, 2938.

Mehta, V. (2013). Evaluating Public Space. Journal Of Urban Design, 19(1), 53-88. http://dx.doi.org/10.1080/13574809.2013.854698

Mneimneh, F., Srour, I., Kaysi, I., \& Harb, M. (2016). Eco-City Projects: Incorporating Sustainability Requirements during Pre-Project Planning. Journal Of Urban Technology, 1-28.

Pediaditi, K., Doick, K., \& Moffat, A. (2010). Monitoring and evaluation practice for brownfield, regeneration to greenspace initiatives. Landscape And Urban Planning, 97(1), 22-36.

Sándor, Zs. P., \& Csiszár, Cs. (2015). Role of Integrated Parking Information System in Traffic Management. Periodica Polytechnica Civil Engineering, 59(3), 327-336. 
Smith, R. (2014). Planning for urban sustainability: the geography of LEED ${ }^{\circledR}-$ Neighborhood Development ${ }^{\mathrm{TM}}\left(\mathrm{LEED}{ }^{\circledR}-\mathrm{ND}^{\mathrm{TM}}\right)$ projects in the United States. International Journal Of Urban Sustainable Development, 7(1), 15-32.

Steeneveld, G., Klompmaker, J., Groen, R., \& Holtslag, A. (2016). An urban climate assessment and management tool for combined heat and air quality judgements at neighbourhood scales. Resources, Conservation And Recycling.

van Leeuwen, E., Vreeker, R., \& Rodenburg, C. (2006). A Framework for Quality of Life Assessment of Urban Green Areas in Europe; An application to District Park Reudnitz Leipzig. International Journal of Environmental Technology and Management, 6, 111-122.

Wende, W., Bond, A., Bobylev, N., \& Stratmann, L. (2012). Climate change mitigation and adaptation in strategic environmental assessment. Environmental Impact Assessment Review, 32(1), 88-93. 